\title{
Use of the consent provisions of the Choice on Termination of Pregnancy Act for live births by caesarean section when unable to follow the procedures in the Children's Act
}

The Children's Act ${ }^{[1]}$ provides that in emergencies the superintendent of a hospital, or the person in charge of a hospital in their absence, may consent to the medical treatment of or surgical operation on a child, subject to two conditions: (i) if the treatment or operation is necessary to preserve the child's life or to save the child from serious lasting physical injury or disability; and (ii) if the treatment or an operation is so urgent that it cannot be deferred to obtain the consent that would otherwise be required.

The Choice on Termination of Pregnancy Act ${ }^{[2]}$ (CTOP Act) provides that pregnancy in the third trimester after the 20th week of gestation may be terminated when its continuation will 'endanger the woman's life' or will 'pose a risk of injury to the fetus'. When an urgent caesarean section is required and there is no time to comply with the provisions in the Act, some doctors have relied on the child's consent alone and applied the third-trimester provisions of the CTOP Act (Dr N F Moran - personal communication, 28 March 2018). Is this practice legal?

I suggest that in such situations doctors may use the consent provisions in the CTOP Act for live births by caesarean section. This Act states that children may consent to termination of pregnancy without assistance from their parents or guardians. The definition of 'termination of pregnancy' in the context of the Act and its purpose are wide enough to cover live birth terminations of pregnancy by caesarean section. ${ }^{[3]}$

Firstly, unlike the previous Abortion and Sterilization $\mathrm{Act}^{[4]}$ and legislation in some US states and in countries such as Zambia and Zimbabwe, the definition of termination of pregnancy in the CTOP Act does not refer to 'abortions' or to 'procuring or inducing a miscarriage. ${ }^{\text {[3] }}$ It simply defines termination of pregnancy as 'the separation of and expulsion, by medical or surgical means, of the contents or the uterus of a pregnant woman', which happens when a caesarean section is undertaken. ${ }^{[3]}$

Secondly, the preamble to the CTOP Act states that it 'repeals the restrictive and inaccessible provisions of the Abortion and Sterilization Act ... and promotes reproductive rights'. In addition, it 'extends freedom of choice by affording every woman the right to choose whether to have an early, safe and legal termination according to her individual beliefs. ${ }^{[2]}$ By allowing a pregnant child to consent to a caesarean section to save her life and comply with her wish to save her unborn child from injury, doctors are 'promoting reproductive rights' and ensuring that the mother is exercising her 'right to have an early, safe and legal termination. ${ }^{\text {[3] }}$

Unless Parliament or the courts restrict the definition of termination of pregnancy in the CTOP Act to the procurement of abortions or the inducement of miscarriages, the existing definition is sufficiently wide to justify doctors using the third-trimester provisions of the Act for live births. Currently, during the third trimester, doctors may rely on the consent of the pregnant child alone in situations where doctors undertake a caesarean section to save the mother's life or to prevent the fetus from suffering the risk of injury in terms of the CTOP Act. ${ }^{[3]}$

Whatever Parliament or the courts decide, in emergencies doctors can always fall back on the 'best interests of the child' constitutional principle. ${ }^{[5]}$ To determine this, doctors should use the provisions in the CTOP Act and standards in the Children's Act as guidelines for determining the pregnant child's 'best interests ${ }^{\text {'[1] }}$ when there is no time to obtain the consent required by the Children's Act. Such an approach is also consistent with the bioethical principles of patient autonomy, beneficence, non-maleficence and justice or fairness. ${ }^{[6]}$

\section{J McQuoid-Mason}

Centre for Socio-Legal Studies, University of KwaZulu-Natal, Durban, South Africa

mcquoidm@ukzn.ac.za

1. South Africa. Children's Act No. 38 of 2005.

2. South Africa. Choice on Termination of Pregnancy Act No. 92 of 1996

3. McQuoid-Mason DJ. Can the consent provisions in the Choice on Termination of Pregnancy Act, which do not require children to be assisted by a parent or guardian, be used for live births by caesarean section in emergency situations? S Afr J Bioethics Law 2018;11(1):43-45. https://doi.org/10.7196/ SAJBL.2018v11i1.644

4. South Africa. Abortion and Sterilization Act No. 18 of 1975

5. Constitution of the Republic of South Africa, 1996.

6. Beauchamp TL, Childress JF. Principles of Biomedical Ethics. 3rd ed. Oxford: Oxford University Press 1994.

S Afr Med J 2018;108(10):805. DOI:10.7196/SAMJ.2018.v108i10.13472 